The Business Meeting received a recommendation from the Council that it consider a resolution not notified in advance to the membership. The resolution was read, accepted as an item of business by four-fifths of the members present and voting (see Article X, Section 1 of the Bylaws), and amended by adding italicized words. The text then debated was the following:

This Business Meeting of the American Mathematical Society, concerned by reports that the esteemed Uruguayan mathematician Jose Luis Massera is in prison and has been held for a considerable period without trial, states its concern for his health and well-being, and calls for his release and the protection of his human rights.

The resolution was passed.

The Business Meeting received a second recommendation from the Council that it consider a resolution not notified in advance to the membership. The resolution was read and accepted by four-fifths of the members present and voting. The text was as follows:

This Business Meeting of the American Mathematical Society calls for the release from prison of Professor of Mathematics, L. A. Ladyženskii of the University of Riga.

The resolution was passed.

The question was raised by Robert $M$. Thrall whether political questions are a proper concern of this Society. The President noted that the general issue has been referred for consideration to the Committee on Principles and Procedures.

The meeting was adjourned at 5:05 P.M.

Bethlehem, Pennsylvania

Everett Pitcher Secretary

PaUl T. BAteman

URBANA, ILLINOIS Associate Secretary

\title{
THE MARCH MEETING IN TALLAHASSEE
}

The seven hundred thirty-second meeting of the American Mathematical Society was held at the Florida Agricultural and Mechanical University in Tallahassee, Florida, March 4-5, 1976. There were 157 registrants including 141 members of the Society.

By invitation of the Committee to Select Hour Speakers for the Southeastern Sectional Meetings, hour addresses were given by B. J. Ball of the University of Georgia, L. Carlitz of Duke University, and R. Kalman from the University of Florida. Professor Marion Tinsley introduced Professor Carlitz who talked about Functions and correspondences in a finite field. Professor James C. Cantrell introduced Professor Ball who talked about Geometric topology and shape theory, and Professor A. R. Bednarek introduced Professor Kalman who spoke about The global theory of the Riccati equation.

There were four special sessions held at this meeting. Each of these special sessions was split into two parts, half held on Thursday afternoon and the other half held on Friday morning. Professor Heron Collins of Louisiana 
State University organized a special session on Strict Topologies which included as participants Professors Steven F. Bellenot, R. A. Fontenot, William H. Graves, Denny Gulick, Dennis Sentilles, W. H. Summers, Donald C. Taylor, and Robert F. Wheeler. Professors Robert Gilmer and J. L. Mott of Florida State University organized a special session on Commutative Rings in which the participants were Professors D. D. Anderson, J. T. Arnold, Hyman Bass, Paul M. Eakin, Eloise Hamann, Stephen McAdam, T.-T. Moh, Judith D. Sally, Arvinash Sathaye, and David Wright. A third special session was organized by Professor Mary-Elizabeth Hamstrom of the University of Illinois. The topic of Professor Hamstrom's session was Geometric Topology and the participants included Professors Frederick D. Ancel, Joan S. Birman, Robert F. Craggs, Robert J. Daverman, Julian Eisner, Marvin Israel, R. C. Lacher, J. G. Hollingsworth, Martin Scharlemann, R. B. Sher, and DeWitt L. Sumners. The fourth special session, on Finite Groups, was organized by Professor Leonard J. Scott, Jr. of the University of Virginia and the participants were Professors Mark Benard, Arnold D. Feldman, Pamela A. Ferguson, Mark P. Hall, Jr., Peter Hoefsmit, Wayne R. Jones, Brian Parshall, and H. N. Ward.

There were also three sessions for contributed papers. These were chaired by Professors Don Hill, Allan G. Anderson, and J. R. Quine.

Professor Wendell Motter was in charge of local arrangements.

TAllahassee, Florida

O. G. HARROLD, JR. Associate Secretary

\section{THE MARCH MEETING IN URBANA}

The seven hundred thirty-third meeting of the American Mathematical Society was held at the University of Illinois at Urbana-Champaign from Monday, March 15 through Saturday, March 20, 1976. There were 377 registrants, including 273 members of the Society.

The period March 15-18 was devoted to a Symposium on Probability, which was supported by the National Science Foundation under a grant to the American Mathematical Society. The topic of the Symposium was selected by the 1974 Committee to Select Speakers for Western Sectional Meetings, which consisted of Richard A. Askey, Paul T. Bateman (chairman), and Donald J. Lewis. The Organizing Committee of the Symposium, responsible for selecting the speakers and arranging the program, consisted of Kai Lai Chung, Joseph L. Doob (chairman), Richard M. Dudley, Ronald K. Getoor, Frank B. Knight, and Frank L. Spitzer. The speakers at the Symposium were Donald L. Burkholder, Hans Föllmer, Jean Jacod, Naresh C. Jain, Harry Kesten, Frank B. Knight, Oscar E. Lanford III, Bernard Maisonneuve, Paul-André Meyer, P. Warwick Millar, Steven Orey, Mark A. Pinsky, Gilles Pisier, William E. Pruitt, Daniel Revuz, Daniel W. Stroock, John B. Walsh, Shinzo Watanabe, and David Williams.

By invitation of the Committee to Select Hour Speakers for Western Sectional Meetings there were three one-hour addresses. Professor Paul Erdös of the Hungarian Academy of Sciences addressed the Society Friday morning 